\title{
Issue relevance and source credibility as a determinant of retention
}

\author{
WILLIAM F. MCDANIEL and LESLIE C. VESTAL \\ Appalachian State University, Boone, North Carolina 28607
}

\begin{abstract}
Forty-four college students were randomly assigned to four groups in which they read a single communication varying in levels (high-low) of source credibility and issue relevance. Immediate retention was assessed by six questions contained on one of two randomly distributed questionnaires. Long-term retention assessment consisted of combining items on the immediate retention questionnaires - thus obtaining two measures, one for identical items and another for new items. Results indicated that source credibility and issue relevance interact with the high source credibility/high issue relevance group retaining a statistically significant greater amount of issue content than the high source credibility/low issue relevance and low source credibility/high issue relevance groups.
\end{abstract}

The postulate that an individual attends more readily to stimuli congruent with his own beliefs, values, and concepts has encouraged study of the interaction of such variables with opinion, learning, memory, perception, etc. Much of this research has concerned the selective learning and retention of controversial materials. Early research by Levine and Murphy (1943), based on the unconfirmed hypotheses of Edwards (1941), demonstrated superior retention of mildly pro-communist subjects for a pro-Soviet communication in comparison to anti-communist subjects and the superior retention of anti-communist subjects for anti-Soviet learning materials. Thus, the effects of subjects' attitudinal variables on memory were demonstrated, and this finding has tended to be supported by some of the subsequent research (Alper \& Korchin, 1952; Jones \& Aneshanel, 1956; Jones \& Kohler, 1958; Taft, 1954; Zimmerman \& Bauer, 1956).

Brigham and Cook (1969), in an experiment paralleling the Levine and Murphy (1943) and the Jones and Kohler (1958) paradigms, failed to confirm the results of the attitude-selective learning hypothesis as well as the postulate that individuals retain plausible statements consonant with the subjects' attitudes better than implausible statements dissonant with the subjects' attitudes. This finding, in conjunction with other similar results (Smith \& Jamieson, 1972; Waly \& Cook, 1966) conflicting with the Levine-Murphy hypothesis, has seriously questioned the generality of attitudinal mediation in the retention of controversial materials and has suggested that other variables may have been confounded with the earlier findings. Dutta and Kanungo (1967) have shown that the intensity of unpleasant and pleasant affects generated by tasks influences later task retention, while Smith and Jamieson (1972) have found ego involvement to be a

Reprint, communication, and questionnaire requests should be sent to William F. McDaniel, Department of Psychology, University of Georgia, Athens, Georgia 30602. major determinant of retention rather than pre-existing attitude.

The present experiment was designed to investigate the effects of stimulus variables contained within the communication upon retention. The roles of relevance of the issue to the subject and credibility of the source reporting the communication in the mediation of retention were examined. It was hypothesized that communications varying with respect to these variables would lead to discernible group differences in retention of issue content.

\section{METHOD}

\section{Subjects and Materials}

Forty-four introductory psychology students of both sexes served as subjects and were assigned randomly to four groups.

Four 300-word written communications, identical except for information pertinent to the variables source credibility and issue relevance, were used. Highly credible communications were defined as those ascribed to "Dr. John A. Wood, PhD, JD," while low credibility communications were defined as those ascribed to rumor. High relevance was defined as a referendum against current laws forbidding the sale of alcoholic beverages in the local county (Watauga, North Carolina). Low relevance was defined as the same referendum, but proposed in a different county in a distant state (Spillwell, Idaho).

Twelve fill-in-the-blank questions were used to assess recall of communication content. These questions were divided into two separate six-item questionnaires which were randomly distributed among subjects as a measure of immediate retention. All 12 items comprised the questionnaire which was used after the communication presentation and the immediate retention test in order to provide the two measures of long-term retention. One measure was the score achieved on the items that the subject received on the immediate retention test, while the second measure consisted of the score obtained on the new items. This was done as a control for possible confounding resulting from the interaction between the independent variables and question rehearsal.

Procedure
Upon entering psychology classes, the experimenters
explained that they were interested in studying aspects of social attitudes. The subjects were offered bonus grade points to 


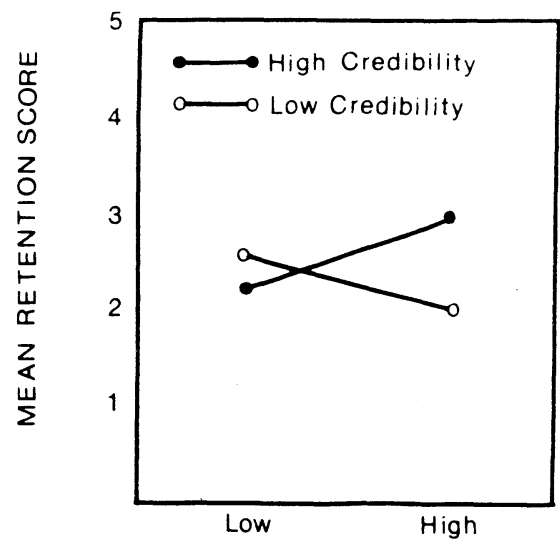

ISSUE RELEVANCE

Figure 1. Mean retention scores for the four groups.

participate. The communication pamphlets were randomly distributed, and the subjects were asked to read the communication silently. After a 10-min interval, the communications were collected and the six-item questionnaires distributed. Subjects were asked to complete the questionnaire within $5 \mathrm{~min}$, after which the questionnaires were collected and the subjects informed that the experimenters would return in 1 week for additional research. One week later, the 12-item questionnaire was presented, and, after $10 \mathrm{~min}$, all questionnaires were collected, and the subjects were debriefed.

Scores on both retention tasks were determined by two paid individuals not associated with the study according to answers specified by the experimenters. One point was assigned for each correct response.

\section{RESULTS}

Each subject's retention of communication content was assessed by scores obtained on the six-item immediate retention questionnaire, the same questions 1 week later and six new questions also 1 week later.

As predicted, variations in levels of source credibility and issue relevance differentially influence communication content retention. Analysis of variance on retention scores (source credibility by issue relevance by retention assessment method) indicates that source credibility and issue relevance interact, $F(1,40)=6.04, p<.025$. Figure 1 demonstrates this interaction where scores for the groups are averaged across the three retention assessment methods. A paired comparisons analysis indicates that the high source credibility/high issue relevance group retained significantly more content than the high source credibility/low issue relevance group, $\mathrm{t}(40)=2.09$, $\mathrm{p}<.05$, and the low source credibility/high issue relevance group, $\mathrm{t}(40)=2.55, \mathrm{p}<.02$. Mean scores for the high source credibility/high issue relevance, high source credibility/low issue relevance, low source credibility/high issue relevance, and low source credibility/low issue relevance groups are, respectively, $3.00,2.18,2.00$, and 2.54 .
The analysis of variance also indicates that retention of communication content varies as a function of the time and method of measurement, $F(2,80)=34.45$, $\mathrm{p}<.001$. A paired comparisons reveals that immediate retention scores are higher than long-term retention measured by the same questions, $\mathrm{t}(80)=4.31, \mathrm{p}<.001$, and long-term retention measured by the new items, $t(80)=8.33, p<.001$. The difference between identical item and new item long-term retention scores, $\mathrm{t}(80)=4.03, \mathrm{p}<.001$, indicates that long-term retention is facilitated on items previously answered. Means for immediate long-term identical and long-term new item retention scores are, respectively, $3.34,2.41$, and 1.54. The nonsignificiant interactions between retention assessment methods and source credibility, issue relevance, and source credibility by issue relevance indicate that questionnaire item rehearsal was not confounded with long-term retention.

\section{DISCUSSION}

The finding of primary importance is that the communication variables source credibility and issue relevance interact to effect immediate and long-term retention of communication content. A controversial communication ascribed to a source of high credibility and of high relevance to the reader has been shown to ameliorate subsequent retention in comparison to communications of high credibility/low relevance and low credibility/high relevance. This finding contributes to the established subject related variables of pre-existing attitude (Levine \& Murphy, 1943), ego involvement (Smith \& Jamieson, 1972), and the intensity of affect generated by the task (Dutta \& Kanungo, 1967), the stimulus variables source credibility and issue relevance.

\section{REFERENCES}

Alper, T. G., \& Korchin, S. J. Memory for socially relevant material. Journal of Abnormal and Social Psychology, 1952, 47, 25-37

Brigham, J. C., \& Cook, S. W. The influence of attitude on the recall of controversial material: A failure to confirm. Journal of Experimental Social Psy chology, 1969, 5, 240-243.

Dutta, S., \& Kanungo, R. N. Retention of affective material: A further verification of the intensity hypothesis. Journal of Personality and Social Psychology, 1967, 5, 476-481.

Edwards, A. L. Political frames of reference as a factor influencing recognition. Journal of Abnormal \& Social Psy chology, 1941, 36, 34-61.

Jones, E. E., \& Aneshanel, J. The learning and utilization of contravaluant material. Journal of Abnormal and Social Psy chology, 1956, 53, 27-33.

Jones, E. E., \& Kohler, R. The effects of plausibility on the learning of controversial statements. Journal of Abnormal and Social Psy chology, 1958, 57, 315-320.

Levine, J. M., \& Murphy, G. Learning and forgetting controversial material. Journal of Abnormal and Social Psy chology, 1943, 38, 507-517.

Smith, S. S., \& Jamieson, B. D. Effects of attitude and ego involvement on the learning and retention of controversial material. Journal of Personality and Social Psychology, 1972, 22, 303-310.

Taft, $R$. Selective recall and memory distortion of favorable and unfavorable material. Journal of Abnormal and Social Psy chology, 1954, 49, 23-28.

Waly, P., \& Cook, S. W. Attitude as a determinant of learning and memory: A failure to confirm. Journal of Personality and Social Psy chology, 1966, 4, 280-288.

Zimmerman, C., \& Bauer, R. A. The effect of an audience upon what is remembered. Public Opinion Quarterly, 1956, 20 , 238-248.

(Received for publication March 8, 1975.) 